\title{
ANALISIS KELAYAKAN USAHA BUDIDAYA JAMUR TIRAM (Pleurotus ostratus) DI KOTA BENGKULU
}

\section{FEASIBILITY ANALISIS OF OYSTER MUSHROOM (Pleurotus Osratus) IN BENGKULU CITY}

\author{
Ees Tari \\ Program Studi Agribisnis Fakultas Pertanian, Universitas Dehasen Bengkulu
}

\begin{abstract}
ABSTRAK
Penelitian ini bertujuan untuk menganalisis sistem pengelolaan, kelayakan usaha, pendapatan dan Break Event Point(BEP) pada industri jamur tiram di Kota Bengkulu. Penelitian dilakukan melalui metode sensus serta pengambilan data primer dan data sekunder, pada industri budidaya jamur tiram yang ada di Kota Bengkulu. Hasil penelitian menunjukan bahwa berdasarkan analisis $\mathrm{R} / \mathrm{C}$ rasio, keempat industri budidaya jamur tiram yang diteliti menunjukan layak, dengan nilai $\mathrm{R} / \mathrm{C}$ rasio untuk Industri Assalamganodarma sebesar 1,64, Industri Jamur Tiram sebesar 1,03, Indutri Raflesia Jamur sebesar 1,99, dan Industri Putri Hijau sebesar 1,63. Total pebdaptaran pertahun yang diperoleh Industri Assalamganodarm adalah Rp. 20.155.000,industri jamur tiram, industri jamur tiram Rp. 29.000.000, industri Raflesia Jamur Rp. 71.032.000 dan Industri Putri Hijau Rp. 50. 265.000. Hasil analisis BEP atau titik impas pada Industri Assalamganodarm sebesar 612,26 kg/tahun, Industri Jamur Tiram $1.400 \mathrm{~kg} / \mathrm{tahun}$, Industri Raflesia Jamur 1.778,4 kg/tahun dan Industri Putri Hijau $1.536,75 \mathrm{~kg} / \mathrm{tahun}$.
\end{abstract}

Kata kunci : Analisis Kelayakan, Jamur Tiram, BEP

\begin{abstract}
This study aimed to analyze the system of management, feasibility, revenue and Break Event Point (BEP) on oyster mushroom industry in Bengkulu City. The study was conducted through acensus method as well as primary data and secondary data, the oyster mushroom cultivation industry in Bengkulu City. The results showed that the Based on the analysisi of $R / C$ ratio, the four industries surveyed oyster mushroom cultivation decent showing, with a value of $R / C$ ratio for Industrial "Assalamganodarma" by 1.64, 1.03 "Jamur Tiram" Industry, "Raflesia Jamur" Industry of 1.99 and "Putri Hijau" Industry 1.63. total revenue per year derived Assalamganodarma Industry is Rp. 20.155 million, "Jamur Tiram" Industry RP. 29 million, "Raflesia Jamur" Industry RP. 71.032 million and "Putri Hijau" Industry RP. 50. 265 million. The results of the Analysis of BEP or Breakeven on Industry Assalamganodarma of $612.26 \mathrm{~kg} /$ year,"Jamur Tiram" Industry $1400 \mathrm{~kg} /$ year, "Raflesia Jamur"Industry $1778.4 \mathrm{~kg} /$ year and "Putri Hijau”Industry $1536.75 \mathrm{~kg} / \mathrm{year}$
\end{abstract}

Keywords: Feasibility Analysis, Oyster Mushroom, BEP 


\section{PENDAHULUAN}

Sektor pertanian memiliki peranan penting dalam pertumbuhandan ketahanan pangan nasional. Menurut Karo Karo (2010) maka pembangunan pertanian harus lebih difokuskan kepada komoditi-komoditi keunggulan yang dapat bersaing di pasar domestik maupun pasar internasional.

Salah satu jamur tiram yang menguntungkan bagi manusia adalah jamur tiram putih (Pleurotus ostreatus). Jamur tiram (Pleurotus ostratus) adalah salah satu jenis jamur kayu yang kandungan protein menempati urutan kedua setelah kacang-kacangan. Jamur tiram termasuk tanaman heterotrofik yang hidupnya tergantung pada lingkungan tempatnya hidup (Cahyana, 2001).

Jamur tiram membutuhkan nutrein yaitu sumber karbon yang dapat diperoleh dari berbagai bahan-bahan selulosa seperti serbuk gergaji. Selain serbuk gergaji jamur tiram membutukan nutrein dalam bentuk fosfor, nitrogen, belerang, kalium serta unsur-unsur lainnya.
Menurut Suriawiria, (1986) jamur tiram sebenarnya unsur-unsur tersebut sudah tersedia di dalam jaringan kayu, Tetapi belum mencukupi untuk kebutuhan jamur tiram putih. Oleh karena itu, perlu penambahan sumber nutrein lain dalam bentuk pupuk yang digunakan sebagai bahan campuran selama pembuatan substrat tanaman.

Dengan usaha budidaya jamur tiram(Pleurotus ostratus) yang memiliki luas lahan yang luas dan memiliki nilai jual yang tinggi, akan meningkatkan penghasilan pendapatan yang besar di Kota Bengkulu.

Bagi seorang petani analisis pendapatan memberikan bantuan untuk mengukur apakah kegiatan usahanya pada saat ini berhasil atau tidak (Supriyanto et al., 2006). Pendapatan usahatani akan berbeda untuk setiap petani, dimana perbedaan ini disebabkan oleh perbedaan faktor produksi, tingkat produksi yang dihasilkan dan harga jual yang tidak sama hasilnya (Ridwan et al.,2008, Nurdin, 2005)

Tabel 1.Usaha Budidaya Jamur Tiram di Kota Bengkulu 2013- 2015

\begin{tabular}{|l|l|l|l|}
\hline Nama Industri & 2013 & 2014 & 2015 \\
\hline Assalamganodarma & 6.000 Baglog & 6.000 Baglog & 6.000 Baglog \\
Raflesia Jamur & 10.000 Baglog & 10.000 Baglog & 20.000 Baglog \\
Putri Hijau & 9.000 Baglog & 9.000 Baglog & 15.000 Baglog \\
Jamur Tiram & 8.000 Baglog & 9.000 Baglog & 10.000 Baglog \\
\hline
\end{tabular}

Sumber : Kota Bengkulu (2013 - 2015) 
Berdasarkan latar belakang di atas mengenai pendapatan usaha budidaya jamur tiram dan memiliki nilai jual yang tinggi peneliti tertarik melakukan penelitian dengan Judul' Analisis Kelayakan Usaha Budidaya Jamur tiram (Pleurotus ostratus) di Kota Bengkulu.

\section{METODE PENELITIAN}

\section{Waktu dan Lokasi Penelitian}

Penelitian ini dilakukan di Kota Bengkulu pada bulan Maret - April 2016. Lokasi penelitian ditentukan secara pusposive yaitusecara sengaja dengan pertimbangan pada seluruh industri usaha budidaya jamur tiram yang ada di Kota Bengkulu yang terdiri dari 4 Industri yaitu Industri Assalamganodarma, Industri Jamur Tiram, Industri Padat Karya, Industri Putri Hijau yang berada di Kota Bengkulu.

\section{Metode Pengambilan Sampel}

Pengusaha yang menjadi respoden merupakan seluruh pengusaha berusaha budidaya jamur tiram di Kota Bengkulu. Teknik pengumpulan data respoden dilakukan dengan mewawancarai pemilik dan pekerja untuk Industri Assalamganodarma 4 orang, Industri Jamur Tiram 2 orang, Industri Raflesia Jamur 9 orang dan Industri Putri Hijau 6 orang usaha budidaya jamur tiram di Kota Bengkulu.

\section{Metode Pengumpulan Data}

Data yang akan dikumpulkan dalam penelitian ini terdiri dari data primer dan data sekunder. Data primer diperoleh dari hasil wawancara kepada pemilik dan pekerja yang berusaha budidaya jamur tiram di Kota Bengkulu yang terkait, website yang terkait, jurnal dan buku.

\section{Metode Analisis Data}

Untuk mengetahui sistem pengelolaan usaha budidaya jamur tiram dan apakah layak untuk diusahakan di Kota Bengkulu akan dianalisis secara deskriptif yaitu dengan membandingkan sistem pengelolaan usaha budidayajamur tiram. Untuk mengetahui tingkat produksi dan pendapatan usaha budidaya jamur tiram di Kota Bengkulu akan dianalisis dengan membandingkan produksi dan hasil pendapatan di daerah penelitian.

Untuk mengetahui besarnya pedapatan pemilik yang berusaha budidaya jamur tiram di Kota Bengkulu dilakukan analisis secara rumus sederhana, dengan fungsi sebagai berikut :

$$
\pi=\mathbf{T R}-\mathbf{T C}
$$

Dimana :

$$
\begin{array}{lll}
\pi & : & \text { Pendapatan Bersih Petani(Rp) } \\
\text { TR } & : & \text { Total Penerimaan(Rp) } \\
\text { TC } & : & \text { Total Biaya(Rp) }
\end{array}
$$

Biaya produksi dihitung dengan rumus

$$
\mathrm{C}=\mathrm{FC}+\mathrm{VC}
$$

Dimana : 
$\mathrm{C}($ Cost $) \quad$ : Biaya Total $(\mathrm{Rp})$

VC (Variabel Cost) : Biaya Pariabel

FC (Fixed Cost) : Biaya Tetap (Rp)

Penerimaan adalah produksi dikali harga jual dengan rumus

$\mathbf{R}=\mathbf{P y} \cdot \mathbf{y}$

Dimana :

$\mathrm{R}$ : Penerimaan

Py : Harga Jual Y (Product) Produksi(Kg)

\section{Mengetahui titik impas (BEP)}

Untuk melihat titik impas (Break Event Point) dimana total revenue sama dengan total cost $(\mathrm{TR}=\mathrm{TC})$ menggunakan rumus BEP (Break Event Point) yaitu

BEP Produksi $=\underline{\text { Total Biaya Produksi }}$ Harga Jual Produksi

BEP Harga = Total Biaya Produksi Total Produksi

\section{Menghitung dengan R/C Ratio (Return cost ratio)}

Rumus R/C Ratio (Return cost ratio). Return cost ratio adalah perbandingan antara penerimaan dengan biaya-biaya yang dikeluarkan selama proses produksi sehingga menghasilkan produk dengan rumus:

$\mathrm{A}=\mathrm{R} / \mathrm{C}$

Dimana :

A = Biaya Oprasional (Return cost ratio)

$\mathrm{R}=$ Penerimaan (Revenue $)$

$\mathrm{C}=\operatorname{Biaya}($ Cost $)$

Kriteria uji :

$\mathrm{R} / \mathrm{C}<1$, usaha budidaya jamur tiram di daerah penelitian tidak layak untuk diusahakan.

$\mathrm{R} / \mathrm{C}>1$, usaha budidaya jamur tiram di daerah penelitian layak untuk diusahakan (Soekartawi, 1995).

\section{HASIL DAN PEMBAHASAN}

\section{Keadaan Umum Usaha Budidaya} Jamur Tiram di Daerah Penelitian

Berdasarkan Tabel 2 juga diketahui bahwa umur pemilik usaha budidaya jamur tiram masih dalam usia produktif yaitu 38-61 tahun.

\section{Tabel 2. Karakteristik Usaha Budidaya Jamur Tiram di Kota Bengkulu}

\begin{tabular}{llccc}
\hline $\begin{array}{c}\text { No Identitas } \\
\text { pengusaha }\end{array}$ & Assalamganodarma & $\begin{array}{c}\text { (INDUSTRI) } \\
\text { Jamur Tiram }\end{array}$ & Raflesia Jamur & Putri Hijau \\
\hline 1. Luas Keseluruhan & $30 \times 25 \mathrm{M}^{2}$ & $11 \times 25 \mathrm{M}^{2}$ & $40 \times 50 \mathrm{M}^{2}$ & 1 (ha) \\
2. Tingkat Pendidikan & SLTA & SLTA & $\mathrm{S} 1$ & $\mathrm{~S} 1$ \\
3.Tenaga Kerja(orang) & 3 & - & 4 & 5 \\
4. Umur Pemilik Usaha & 38 & 42 & 55 & 61 \\
5. Mulai Berdirinya Usaha & 2009 & 2013 & 2003 & 2011 \\
6.Jumlah Baglog & 6.000 & 10.000 & 20.000 & 15.000 \\
\hline
\end{tabular}

Sumber : Data primer (2015) 
Tingkat pendidikan pengusaha yang tamat

SLTA dan S1 menunjukkan bahwa pengusaha memiliki kemampuan berfikir dengan wawasan yang cukup luas serta memiliki pengalaman selama untuk Kelurahan Tugu Hiu 4 tahun, Kelurahan Kebun Tebeng 10 tahun, Kelurahan Padat Karya 5 tahun, dan Kelurahan Betungan 7 tahun sehinga dalam mengusahakan budidaya jamur tiram tidak mengalami kesulitan.

\section{Sistem Pengelolaan Usaha Budidaya} Jamur Tiram

Sistem pengelolaan usaha budidaya jamur tiram yang berada di Kota Bengkulu sudah sedikit moderen karena menggunakan mesin pres dan alat sterelisasi lahan kumbung dalam pembuatan baglog, penyemaian atau penanaman bibit jamur tiram dalam baglog dan pemanenan.

\section{Pengelolaan lahan}

Sebelum lahan dibuat kumbung untuk menanam jamur tiram sebaiknya agar hasil yang baik perlu dilakukan pembersihan terlebih dahulu dan setelah dibuat kumbung untuk tempat penanaman jamur tiram perlu disterilkan dahulu dari hama dan penyakit yang akan menghambat pertumbuhan jamur tiram itu sendiri. (Sumarsih, 2003).

\section{Pemeliharaan di Dalam Kumbung}

Pemeliharaan didalam kumbung dilakukan jika miselium dalam baglog sudah penuh 2/3 bagian sudah terpenuhinya umur (1 bulan) pada dasarnya tumbuh buah jamur tiram akan terbentuk apabila baglog sudah terpenuhi mishelium dan didalam kumbung diberi pengatur suhu supaya bisa melihat dengan kelembaban dan kepanasan yang dinamakan (termometer) (Suharjo, 2015).

\section{Pemanenan}

Pemanenan penelitian ini dilakukan apabila jamur tiram bilah ukuranya sudah optimal. Cirinya tudung jamur tiram suda tebal membesar tetapi belum pecah dan umur panen umumnya pada hari ke -45 atau 4-5 hari setelah pembentukan tubuh buah. Hasil panen yang baik produktivitasnya mencapai 300-400 gram dari satu baglog. Pemanenan jamur tiram dapat dilakukan secara manual yang dipetik menggunakan tangan, pemanenan sebaiknya dilakukan disore hari tujuannya agar supaya untuk mencegah bobot jamur yang berkurang. Apabila pemanenan dilakukan pada siang hari, ketika suhu kumbung sedang tinggi, dikhwatirkan bobot jamur tiram akan turun drastis. 
Tabel 3. Analisis Penerimaan Usaha Budidaya Jamur Tiram di Kota Bengkulu

\begin{tabular}{l|lcccc}
\hline No & Nama Industri & Jumlah baglog & $\begin{array}{c}\text { harga } \\
(\text { Rp) }\end{array}$ & $\begin{array}{c}\text { Total } \\
\text { Biaya }\end{array}$ & $\begin{array}{l}\text { Total } \\
\text { Penerimaan }\end{array}$ \\
\hline 1. & Assalamganodarma & 6.000 & 20.000 & 12.245 .200 & 32.400 .000 \\
2. & Jamur tiram & 10.000 & 20.000 & 28.000 .000 & 57.000 .000 \\
3. & Raflesia jamur & 20.000 & 20.000 & 35.568 .000 & 102.600 .000 \\
4. & Putri hijau & 15.000 & 20.000 & 30.735 .000 & 81.000 .000 \\
\hline
\end{tabular}

Sumber : Data Primer 2015)

Dari Tabel 3 menunjukkan bahwa harga jamur tiram $1 \mathrm{~kg}$ yaitu sebesar $\mathrm{Rp}$ 20.000,-. Dari penelitian keempat tempat yang ada di Kota Bengkulu yang berada di Kelurahan Tugu Hiu, Kelurahan Kebun Tebeng, Kelurahan Padat Karya, dan Kelurahan Betungan yang mempunyai penerimaan yang berbeda dan biaya juga berbeda. Pada usaha Kelurahan Tugu Hiu dengan penerimaan sebesar $\mathrm{Rp}$ 32.400.000,- dalam 3 kali menanam jamur tiram. Penerimaan Kelurahan Kebun Tebeng sebesar Rp 57.000.000,- dalam 3 kali menanam dengan 10.000 baglog jamur tiram. Penerimaan Kelurahan Padat Karya sebesar 102.600.000,- dalam 3 kali menaman dengan 20.000 baglog jamur dalam satu tahun. Pada Kelurahan Betungan penerimaan sebesar $\mathrm{Rp}$ 81.000.000,- dalam 3 kali menanam denagan 15.000 baglog jamur tiram.

Biaya yang dikeluarkan dalam usaha budidaya jamur tiram yang ada di Bengkulu yaitu di Kelurahan Tugu Hiu, Kelurahan Tebeng, Kelurahan Betungan, dan Kelurahan Padat Karya merupakan dari semua penjumlahan biaya produksi yaitu biaya tetap dan biaya tidak tetap.

\section{Analisis Pendapatan Usaha Budidaya Jamur Tiram di Kota Bengkulu}

Pendapatan bersih yang berbeda dalam usaha budidaya jamur tiram yang dihasilkan selama satu tahun dalam $3 \mathrm{x}$ tanam dengan pendapatan tertinggi kelurahan padat karya dengan nama usaha raflesia jamur sebesar Rp 67.032.000,sedangkan pendapatan terendah yaitu kelurahan Tugu Hiu dengan nama usaha Assalamganodarma sebesar Rp 20.155.000,-.

\section{Analisis R/C Usaha Budidaya Jamur Tiram}

Kelurahan Tugu Hiu dengan R/C 1,64, Kelurahan Kebun Tebeng dengan R/C 1,03, Kelurahan Padat Karya dengan R/C 1,99,sedangkan Kelurahan Betungan dengan R/C 1,63 semuanya layak untuk diusahakan walaupun tempat penelitian tergolong ada yang baru dan ada juga yang lama dengan total penerimaan dibagi dengan biaya yang dikeluarakan satu 
tahun dengan $3 \mathrm{x}$ menanam jamur tiram dalam 1 tahun..

Gambar 1. menunjukkan bahwa usaha Assalamganodarma untuk BEP produksi sebesar 612,26 kg/tahun dan BEP harga sebesar Rp 20.000. Artinya BEP Produksi dan BEP Harga usaha budidaya jamur tiram tempatnya di Kelurahan Tugu Hiu mengalami titik impas ( Data Primer 2015).

Gambar 2 menunjukkan bahwa usaha Jamur Tiram untuk BEP produksi sebesar $1.400 \mathrm{~kg} / \mathrm{tahun}$ dan BEP harga sebesar
Rp20.000. Artinya BEP Produksi dan BEP Harga usaha budidaya jamur tiram tempatnya di Kelurahan Kebun Tebeng mengalami titik impas( Data Primer 2015).

Gambar 3 menunjukkan bahwa usaha Raflesia Jamur untuk BEP produksi sebesar 1.778,4 kg/tahun dan BEP harga sebesar Rp20.000. Artinya BEP Produksi dan BEP Harga usaha budidaya jamur tiram tempatnya di Kelurahan Padat Karya mengalami titik impas ( Data Primer 2015)

\section{Analisis Break Even Point (BEP) Titik Impas Usaha Jamur Tiram}

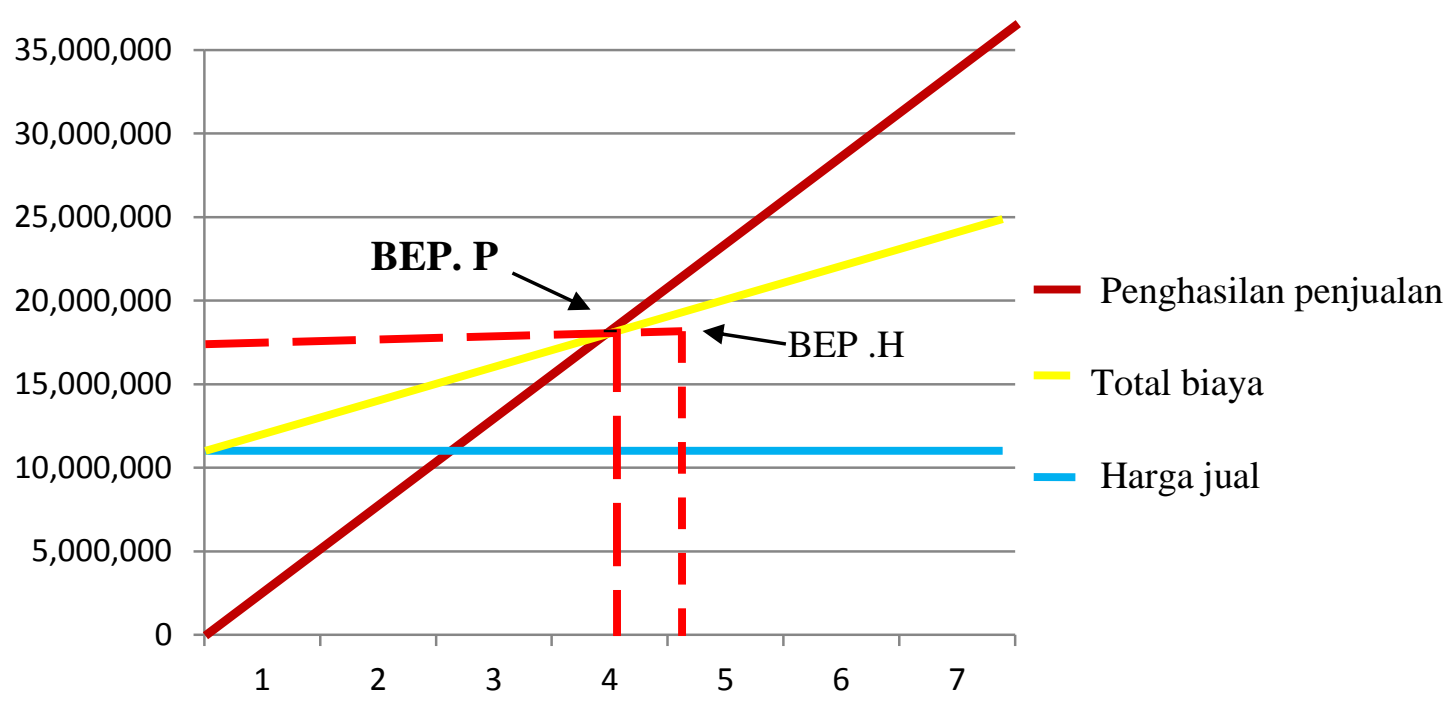

Gambar 1. Kurva BEP Produksi dan Kurva BEP Harga Usaha Assalamganodarma 


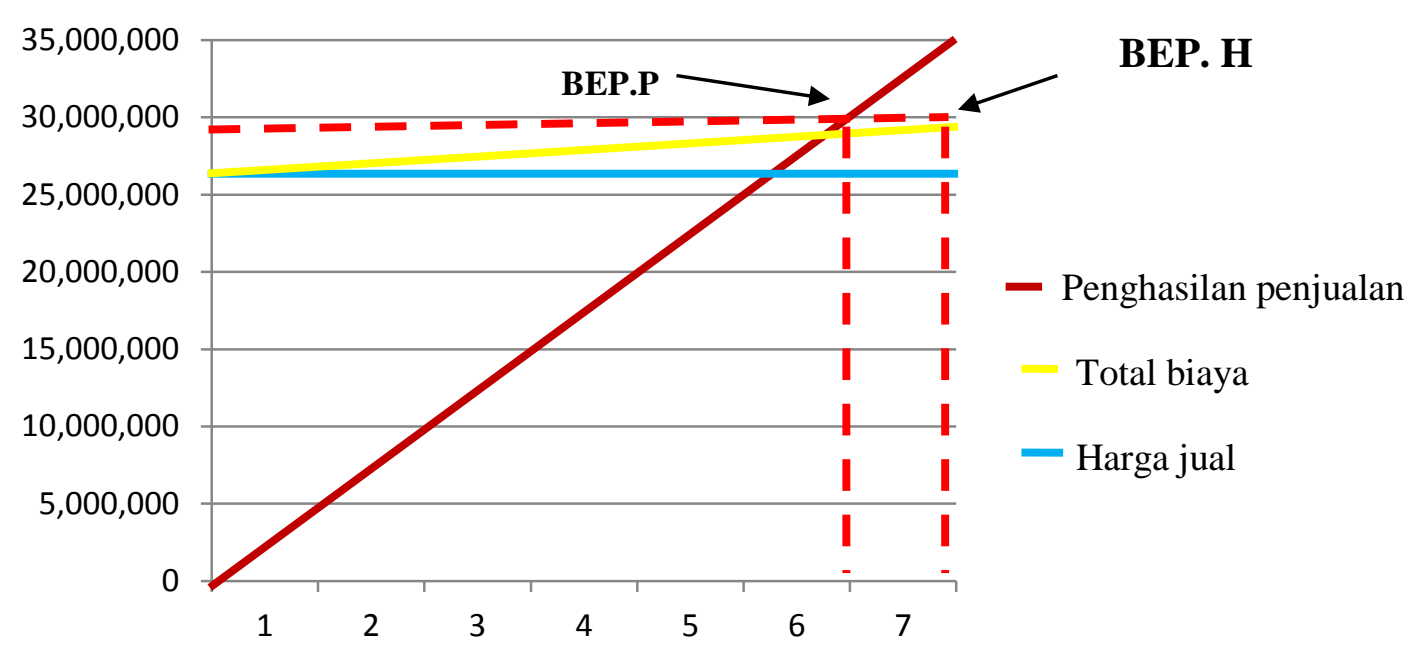

Gambar 2. Kurva BEP Produksi dan Kurva BEP Harga Usaha Jamur Tiram

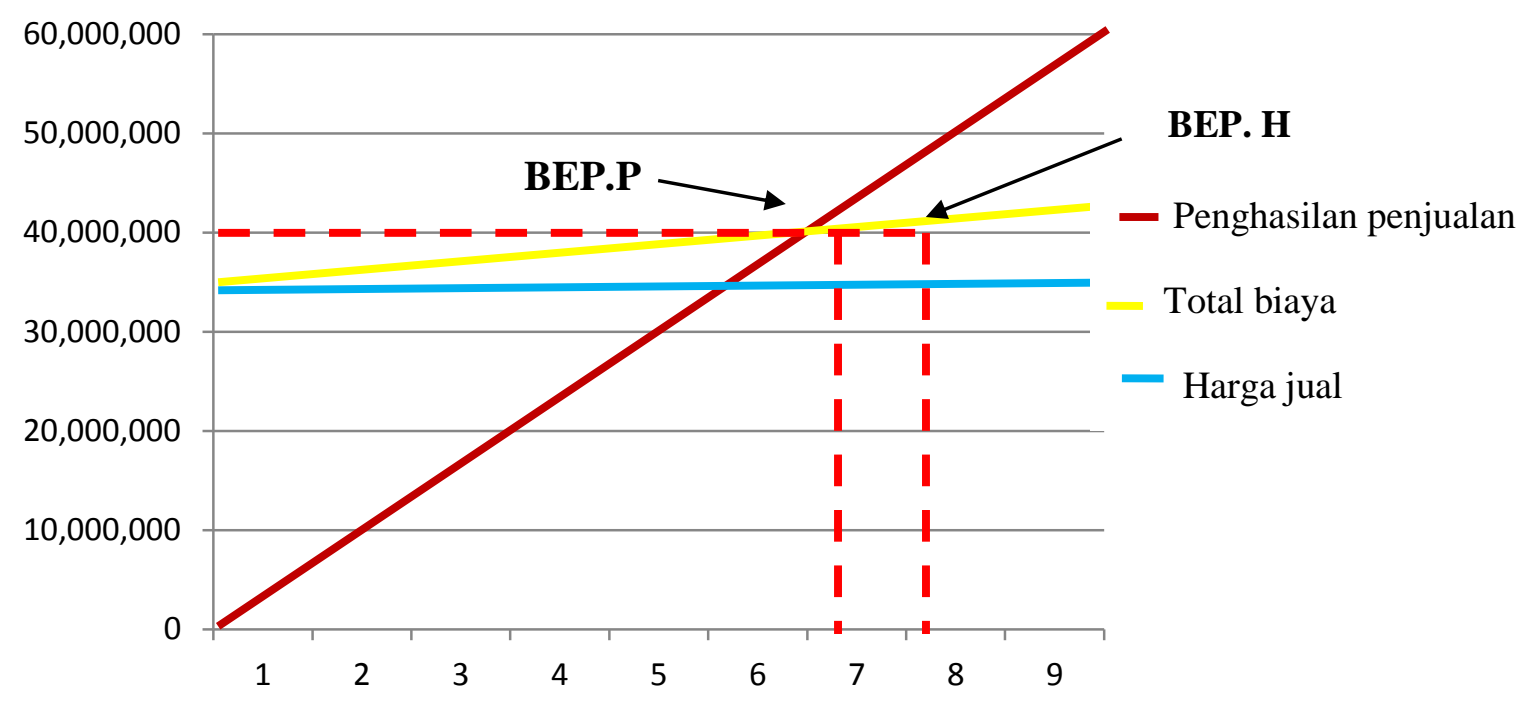

Gambar 3. Kurva BEP Produksi dan Kurva BEP Harga Usaha Raflesia Jamur

Gambar 4. menunjukkan bahwa usaha Putri Hijau untuk BEP produksi sebesar $1.536,75 \mathrm{~kg} / \mathrm{tahun}$ dan BEP harga sebesar Rp20.000. Artinya BEP Produksi dan
BEP Harga usaha budidaya jamur tiram tempatnya di Kelurahan Betungan mengalami titik impas (Data Primer 2015) 


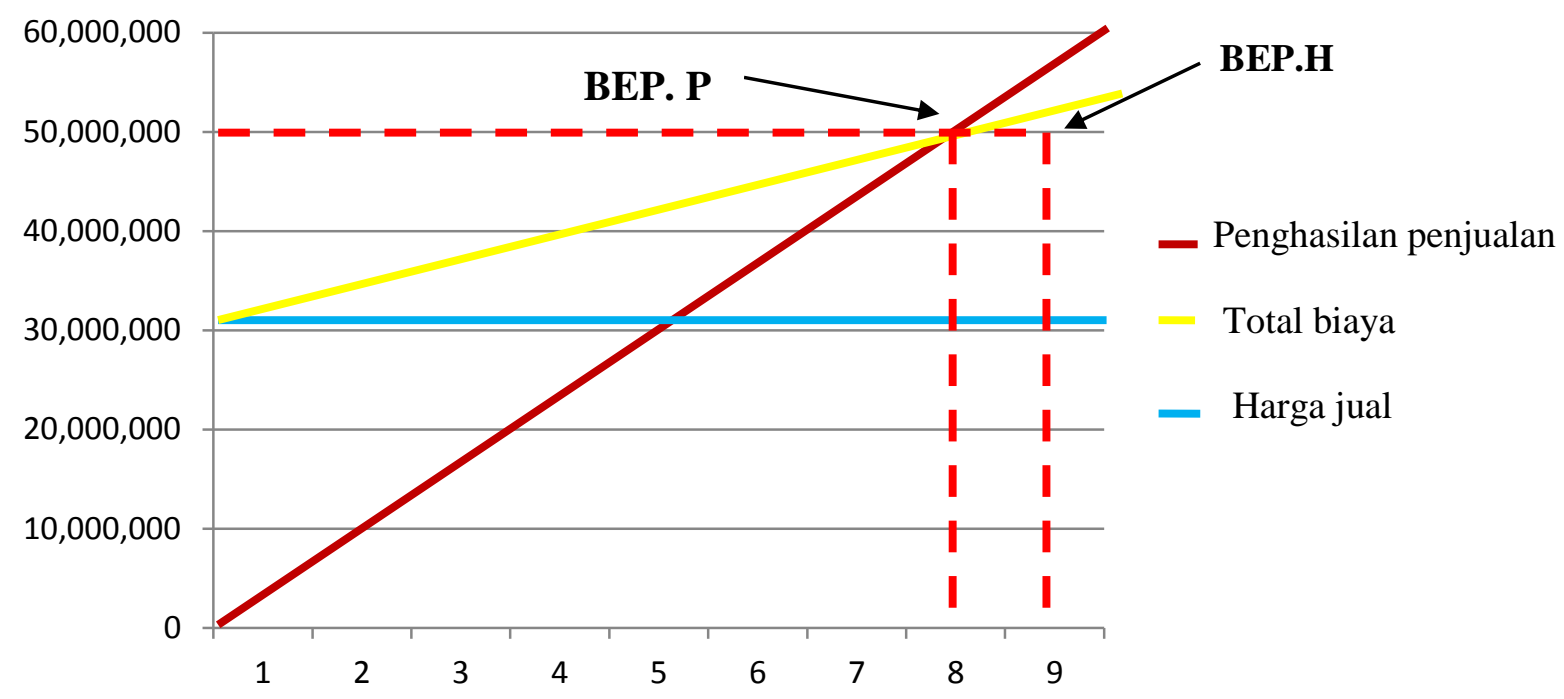

Gambar 4. Kurva BEP Produksi dan Kurva BEP Harga Usaha Putri Hijau

\section{KESIMPULAN}

1. Sistem pengolahan usaha budidaya jamur tiram yang ada di Kota Bengkulu yang berada di Kelurahan Tugu Hiu, Kelurahan Kebun Tebeng, Kelurahan padat Karya dan Kelurahan Betungan yang merupakan pengolahan jamur tiram mulai dari pembuatan baglog, pemeliharan sampai dengan panen masih tergolong sederhana.

2. Total pendapatan bersih dalam satu tahun 3 kali penanaman jamur tiram di Kota Bengkulu yang berada di Kelurahan Tugu Hiu sebesar Rp20.245.200,- Kelurahan Kebun Tebeng sebesar Rp29.000.000,Kelurahan Padat Karya sebesar Rp71.032.000,- dan Kelurahan Betungan sebesar Rp50.265.000,-. dari pendapatan keempat tempat industri usaha budidaya jamur tiram yang terbesar adalah Kelurahan Padat Karya yang memimiliki luas yang berbedah dan penanaman baglog juga berbedah.

3. Analisis $\mathrm{R} / \mathrm{C}$ ratio pada usaha budidaya jamur tiram yang ada di Kota Bengkulu yang berada di Kelurahan Tugu Hiu, Kelurahan Kebun Tebeng, Kelurahan Padat Karya, dan Kelurahan Betungan secara ekonomis layak diusahakan.

4. Analisis BEP titik impas dari keempat tempat usaha budidaya jamur tiram yang ada di Kota Bengkulu yang berada di Kelurahan Tugu Hiu, Kelurahan Kebun Tebeng, Kelurahan Padat Karya, dan Kelurahan Betungan tidak mengalami kerugian tetapi mengalami keuntungan dar $\sim \mathbf{r} \mathrm{h}$ melampui titik impas. 


\section{DAFTAR PUSTAKA}

Anonim, 2014. Budidaya Jamur Tiram (Pleurotus ostreatus). SEAMEO BIOTROP BOGOR. Jawa Barat.

Ambarwati, 2009. Budidaya jamur tiram putih (Pleurotus ostreatus) pada jerami. Fakutas Pertanian. Yogyakarta.

Dinas Pertanian dan Ketahanan Pangan, 2015. Prospek Pengembangan Budidaya Jamur Diram. Bengkulu

Gray, 2002. Menghitung menggunakan (IRC ratio). PT. Agromedia jakarta

Herbagiandono, $1987 . \quad$ Analisis pendapatan jamur tiram. Pers. Jakarta

Karo - Karo. 2010. : Kebijakan yang Tidak Tepat Sasaran. (Online) Tersedia : http: Wk. Staff. Ipb. Ac. $\underline{i d}$ (04 Februari 2016)

Sumarsih Sri, 2013. Budidaya Jamur Tiram dan Bibit Jamur Tiram (Pleurotus ostreatus). Yogyakarta

Syarifuddin, 1990. BEP. Tititk impas. Yogyakarta

Syarifuddin, 1990. Teknologi Jamur Konsumsi, (Jurusan Agroteknologi Fakultas Pertanian). UPN. Yogyakarta.
Suharjo Enjo, 2010. Bertanam Jamur Merang Di Media Kardus , Limbah Kapas, dan Limbah Pertanian. PT agromedia fustaka. Jakarta

Suharjo Enjo, 2015. Budidaya Jamur Tiram Dengan Media Kardus. PT Agromedia Fustaka. Jawa Barat

Soekartiwi, 2001. Ilmu Usaha Tani. Pers . Jakarta

Soekartawi, 2003. Prinsip Ekonomi Pertanian dan Pengembangan Petani Kecil. Pers . Jakarta

Suriawiria, 2015. Budidaya Jamur Tiram . Penebar Swadaya. Jakarta

Prawirokusumo, 2005. Ilmu Usaha Petani. Pers. Jakarta

Pindrik, 2005. Analisis Produksi, Pendapatan Usaha Budidaya Jamur Tiram. Sosial Ekonomi Pertanian. Sekampung Upik Lampung Timur

Prayudi, 2010. Tanaman cabai mera. Universitas Pertanian Bogor (IPB)

Pamungkas, 2000. Pengolahan lingkungan dan penambahan molase pada jamur tiram . Gapkindo. Jakarta. 